\author{
М.С. Русакова
}

\title{
ТИПОЛОГИЧЕСКИЙ И РОЛЕВОЙ ПОДХОДЫ К КОМАНДООБРАЗОВАНИЮ: СРАВНИТЕЛЬНЫЙ АНАЛИЗ ПРОЦЕССОВ РОЛЕВОГО РАСПРЕДЕЛЕНИЯ
}

\begin{abstract}
Аннотация. Статья посвящена эмпирическому сопоставлению особенностей процесса распределения ролей в командах, созданных посредством альтернативных технологий командообразования. Рассмотрению подлежат два наиболее разработанных подхода к комплектованию команды - типологический и ролевой. Исследование демонстрирует специфику каждого из подходов в отношении ряда вопросов распределения ролей членов команд. $B$ частности, рассматриваются такие проблемы, как согласованность и устойчивость процесса распределения ролей, степень легкости категоризации ролевого поведения членов команды, особенности отношения участников к происходящим в команде процессам. Рассматриваются изменения данных показателей в зависимости от трех наиболее актуальных и естественно сменяющих друг друга условий совместной деятельности. Данные условия воссоздаются в ходе двухфакторного многоуровневого эксперимента. Первым условием взаимодействия членов команды выступает контекст низкой осведомленности игроков об особенностях ролевого поведения друг друга. Второе условие совместной деятельности предполагает закономерное накопление опыта командного взаимодействия, в то время как третье условие моделирует деятельность в условиях изменений, с которыми длительно функционирующей команде неизбежно приходится сталкиваться. Исследование показывает, что применение типологического подхода приводит к более напряженным процессам ролевого распределения, первоначально формируя в команде взаимные иллюзии участников относительно друг друга. Временной фактор и условия изменений способствуют активной конструктивной перестройке системы ролей. В то же время внедрение ролевого подхода сопряжено с замедленным и достаточно корректным формированием данной системы, оказывающейся, однако, менее устойчивой к стрессовым условиям деятельности.

Ключевые слова: командная роль, интеллектуальная роль, психологический тип, ролевой репертуар, ролевое распределение, ролевой подход, типологический подход, комплектование, командообразование, команда.

Abstract. The article is devoted to the empirical experimental comparison of characteristics of the process of allocating roles in the teams created by means of alternative technologies of teambuilding. The consideration of the subject, the two most developed approach to the acquisition team - typological and role-playing. The study demonstrates the specificity of each approach in relation to the number of issues of team roles. In particular, we consider issues such as consistency and stability of the process of role allocation, ease of role behavior categorization, participants' attitudes to the team processes. Discusses the changes of these indicators depending on the three most relevant and naturally successive terms of joint activities. The first condition is the interaction of team members in the context of low awareness about the features of role behavior of each other, in other words, at the stage of the first step. The second condition of the joint activity involves the accumulation of experience of team interaction, while the third condition models the operation in terms of that long-functioning team inevitably has to face. The study shows that the application of the typological approach leads to more intense processes of role allocation, initially generating in team the mutual illusions of the participants relative to each other. The time factor and the conditions of change promote active and constructive restructuring of the system roles. At the same time, the introduction of a role-playing approach involves slow enough and the correct formation of the system, appearing, however, less resistant to stressful conditions of environment. Key words: intellectual role, psychological type, role repertoire, role allocation, role-playing approach, typological approach, recruitment, team building, team, team role.
\end{abstract}

$\mathrm{H}$ арастающая тенденция к гуманизации профессиональной деятельности приводит к тому, что в современном мире человеку все реже приходится осуществлять выбор между требованием высокой эффективности своего труда и стремлением к личностной самореализации. Синтез этих направлений становится возможен в том числе благодаря практике 


\section{Горизонты психологии}

командообразования: именно в такой высокопродуктивной группе как команда индивид обретает возможности для раскрытия своего потенциала. Наиболее полно данный вопрос рассматривается в практике командообразования на основе комплектования: предполагается, что тщательный отбор индивидов по персональным характеристикам задает уникальную совокупность их особенностей, повышающую эффективность всей команды. Реализация этих качеств происходит в системе ролей, посредством процесса их распределения, в ходе чего каждая роль как отражение особого набора качеств индивида получает признание со стороны коллег по команде, и соответственно, кредит доверия группы на ее исполнение $[13,14]$.

В рамках такого способа комплектования выделяют типологический и ролевой подходы. Типологический подход предполагает, что в команде формируется система интеллектуальных ролей, определяемая глубинными психологическими типами игроков, то есть системой личностных диспозиций. В ролевом подходе действуют иные роли, командные, являющиеся отражением конкретных компетентностей членов команды, например знаний и умений.

Основным различием между типологическим и ролевым подходами является уровень, на котором происходит комплектование. В типологическом подходе данный уровень более глубинный, опосредующий множество личностных проявлений индивида, в том числе и его внекомандную активность. Способом определения склонности к той или иной интеллектуальной роли выступают личностные опросники и биографическое интервью.

Подобная специфика типологического подхода отдалено определяется историей его возникновения. Основоположником подхода выступил известный швейцарский психиатр К. Г. Юнг. Им же и было введено понятие «психологический тип», использовавшееся для обозначения личностных предрасположенностей, основных, устойчивых направленностей личности, которые в его концепции различались по источнику получения так называемой психической энергии, способу восприятия окружающего мира и по принципу принятия жизненно важных решений. Позднее получившие широкую известность И. Майерс и К. Бриггс дополнили эту классификацию еще одним критерием - ориентацией на процесс или результат, что увеличило количество типов до 16 [3]. Однако громоздкость этой модели оказалась ее существенным недостатком, и в 1950-х гг. американский психолог Д. У. Кейрси систематизировал эти типы, сократив их до четырех основополагающих [7]. Мо- дель Д. У. Кейрси явилась эклектичной с точки зрения своей методологии, однако благодаря этому позволила сделать акцент на ином понятии - интеллектуальная роль, отражающем поведенческие корреляты более абстрактного психологического типа. Благодаря тому что в данной модели отчетливо прописаны особенности совместимости интеллектуальных ролей и их специфика, она вошла в практику командообразования и остается фактически единственной разработанной моделью в типологическом подходе.

История альтернативного ролевого подхода более краткая. Его истоки кроются в интеракционизме, зародившемся как социально-психологическая ориентация в первой трети XX в. под влиянием взглядов Дж. Мида. Целью интеракционизма является изучение социального взаимодействия, или же интеракций. Один из видов интеракционистской ориентации получил название «теория ролей». В первую очередь благодаря ему и были сформированы современные многочисленные взгляды на проблему командной роли, преимущественно в контексте использования команд в организациях. На данный момент наиболее известными моделями, разработанными в этом направлении, выступают модели Ч. Дж. Маргерисона - Д. МакКена, И. К. Адизеса, М. Г. Ярошевского, Р. М. Белбина, М. Геллерта К. Новака [1, 2, 4, 9, 12].

В ролевом подходе, в отличие от типологического уровень комплектования, наоборот, более поверхностный, то есть тесно связан с непосредственно наблюдаемым поведением членов команды в ходе совместной деятельности, их оценками деятельности друг друга. Соответственно, командная роль определяется методом наблюдения, в частности ситуационно-поведенческого тестирования.

Таким образом, предполагается, что два различных способа отбора участников в команду задают две принципиально иные системы командных ролей. Однако, оба уровня комплектования в действительности проявляются параллельно: любое взаимодействие может быть описано как через систему личностных ориентаций, так и компетентностей. И тем не менее, даже этот очевидный факт не позволяет отождествлять подходы, более того, как раз и порождает ключевой вопрос, связанный со степенью их проработанности. Каждый из подходов основан на базовой идее о гетерогенности состава команды, то есть о разнообразии ее членов по существенным для команды характеристикам. Сбалансированная определенным образом гетерогенность приводит к небезызвестному эффекту синергии, теоретически и отличающему команду от более рядовой рабочей группы [15]. Верно и об- 


\section{Психология и психотехника 11(98) • 2016}

ратное: разбалансированная и недостаточно гетерогенная система командных ролей теоретически должна приводить к снижению эффективности, конфликтам и прочим затруднениям [16].

На практике же целенаправленное комплектование команды на уровне одного из двух подходов означает неконтролируемое внесение изменений в систему ролей с точки зрения другого. Вопрос о создании необходимого уровня гетерогенности и обеспечении его баланса в каждом случае прорабатывается либо для уровня личностных диспозиций, либо для уровня компетенций, но не для обоих уровней сразу. Таким, образом, степень разнообразия и упорядоченности системы ролей, согласно каждому из подходов не может и не должна быть отслежена на альтернативном уровне. Иными словами, типологический подход потенциально представляет собой некорректно реализованный ролевой, а ролевой - некорректно реализованный типологический.

Тем не менее, теоретическое рассмотрение столь значимого противоречия, как оказывается, не имеет места в литературе в силу отсутствия выраженного интереса сторонников данных подходов к научно-практическим взглядам оппонентов [10]. В силу этого проведенное исследование направлено на установление возможностей и ограничений типологического и ролевого подходов в отношении процесса распределения ролей, позволяя изучить специфику интеграции личностного потенциала членов команды в различные по своему уровню системы ролей. Помимо гуманистической ориентации поставленного вопроса, анализ специфики процесса ролевого распределения в каждом из подходов способствует дальнейшему раскрытию рефлексивных ресурсов всей команды. Последнее становится возможным в силу того, что проведенное исследование содержит значительный объем сведений об особенностях внутрикомандного взаимодействия игроков в ряде условий.

\section{Организация эмпирического исследования} базовых подходов к комплектованию команды

План исследования представлен двухфакторным и многоуровневым экспериментом. В качестве зависимой переменной выступает ряд характеристик команд. Для данной статьи как ключевые будут выделены следующие:

- согласованность оценок членов команды относительно времени, затраченного на выполнение роли, отражающая восприятие группой совокупности исполняемых каждым игроком ролей, то есть его ролевого репертуара,
- согласованность оценок членов команды относительно качества выполнения ролей коллегами,

- яркость ролевого репертуара членов команды, определяемая как легкость категоризации роли коллеги остальными участниками,

- удовлетворенность членов команды исполнением ролей друг друга,

- степень фактической гетерогенности, то есть степень разнообразия ролей, исполняемых членами команды в ходе совместной деятельности,

- степень совпадения теоретически заданной ролевой структуры, то есть на этапе комплектования, и совокупности ролей, проявившихся на практике, в ходе решения командных задач. В качестве независимой переменной в исследовании выступают фактор способа комплектования, заданный типологическим или ролевым подходом, и фактор условия совместной деятельности, заданный тремя качественными уровнями:

- этапом первого шага, описывающим деятельность игроков только что сформированной команды, еще не имеющих опыта взаимодействия друг с другом;

- этапом стабильности, на котором команды продолжают решать новые задачи, приобретая опыт совместной деятельности;

- этапом условий изменений, в которых команды вынуждены внезапно изменить привычный способ решения задач.

Гипотеза исследования предполагает, что команды, укомплектованные на основе типологического подхода, по сравнению с командами, укомплектованными на основе ролевого подхода, имеют большие сложности, связанные с процессом распределения ролей. Основополагающей причиной этого допущения выступает тот факт, что типологический подход в силу теоретических принципов своей реализации не предполагает практического выстраивания прямых связей между психологическими типами игроков и их интеллектуальными ролями.

В ходе основного исследования 200 участников основного эксперимента в возрасте 20-25 лет были объединены в 40 команд численностью 3-7 человек: по 20 команд для каждого подхода, как типологического, так и ролевого.

В силу того что оба подхода отличаются высокой степенью своей разработанности преимущественно на этапе комплектования, качестве последующей независимой модели командообразования выступила модель Ю. М. Жукова [6]. Данная модель благодаря включенным в нее этапам 


\section{Горизонты психологии}

рефлексии позволяет воссоздать в команде насыщенный событийный контекст, который, в свою очередь, способствует более четкому восприятию членов команды субъективных разграничений изменений в распределении ролей других участников с течением времени.

Команды решали интеллектуальные игровые задачи, соответствующие трем условиям совместной деятельности. Все задания были модифицированы под задачи данного эксперимента и носили принципиально различный характер, чтобы избежать влияние типа задачи на полученные результаты. Первое предполагало постройку башни из бумаги по трем несовместимым критериям. Второе задание имитировало расследование преступления, содержащее множественные альтернативные версии. Первое и второе задания целенаправленно не были связаны с условиями совместной деятельности, в силу чего в каждом подходе одна половина команд получала в качестве первого задания задачу «Башня», в то время как вторая половина - задание «Расследование убийства». Третье задание было авторским и моделировало условия изменений, с которыми рано или поздно неизбежно сталкивается любая команда. Данное задание предполагало сборку картины-танграма с этапом самопроверки, неожиданно демонстрирующим игрокам неэффективность их прежнего способа действия в условиях дефицита времени.

После каждого этапа участники осуществляли рефлексию взаимодействия, заполняя оценочные листы, специально разработанные для данного эксперимента. Оценивание ролевого поведения коллег по команде осуществлялось в соответствии с типологической моделью Д. У. Кейрси, являющейся, по сути, единственной оптимальной моделью комплектования в рамках этого подхода, и с наиболее типичной для ролевого подхода моделью М. Геллерта и К. Новака.

Анализ данных осуществлен посредством таких статистических критериев, как U-критерий Манна-Уитни, G-критерий знаков, Т-критерий Вилкоксона, коэффициент конкордации Кендалла. Однако в силу естественно присутствующих многочисленных перцептивных искажений, возникающих у членов команды при оценивании ролевого поведения коллег, применен дополнительный аналитический метод G-критерия знаков для методов описательной статистики, позволяющий выделить скрытые взаимосвязи. Углубленный анализ данных показал наличие специфики каждого из подходов применительно к процессам ролевого распределения.

\section{Особенности ролевого распределения в типологическом и ролевом подходах в зависимости от условий совместной деятельности}

На первом этапе эксперимента в условиях первого шага команды, укомплектованные на основе $\boldsymbol{m u}$ пологчческого подхода, в сравнении с ролевыми командами демонстрируют иллюзорную легкость протекания процессов ролевого распределения. Еще до накопления полноценного опыта взаимодействия, судя по повышенному показателю яркости ролевого репертуара ( $\mathrm{p}=0,010)$, члены команды оказываются весьма уверенны в верности определения интеллектуальных ролей друг друга.

Очевидно, что практическая целесообразность данного факта всецело зависит от корректности подобных взаимных оценок, которая, как показывает исследование, оказывается отнюдь невысокой. Примечательным является уже то, что на уровне тенденции в таких командах наблюдается меньшая степень согласованности оценок по времени и качеству исполнения роли среди всех членов команды. По сути, ролевое поведение каждого игрока на этом этапе обозначается лишь условно и не отражает всей совокупности групповых ожиданий, как того предполагает подход, но при этом уже формирует достаточно разобщенные представления участников друг о друге.

Такому эффекту способствуют и меньшее количество ролей в типологической модели, и предварительная рефлексивная работа по заполнению опросника Д. У. Кейрси, побуждающая участников обратиться к образу своего идеального Я до начала эксперимента. Естественная исходная низкая осведомленность членов команды о поведении друг друга создает дополнительные возможности для реализации участниками своего идеального Я посредством самопрезентации с ориентацией на исполнение идеализированной интеллектуальной роли [5]. Действительно, выявленная на уровне тенденции большая степень расхождения теоретической (заложенной в рамках комплектования) и эмпирической (проявившейся в ходе экспериментального взаимодействия) ролевой структур в типологическом подходе демонстрирует, что члены «типологических» команд на этапе первого шага чаще склонны реализовывать себя как представителей интеллектуальных ролей, не свойственных их психологическому типу. В этом проявляется ожидаемый практический разрыв между психологическим типом и интеллектуальной ролью: последняя для своей реализации нуждается в накоплении специфического практического опыта. 


\section{Психология и психотехника 11(98) • 2016}

В «типологических» командах позиционирование остается искаженным до конца первого этапа, в силу того что для обнаружения несоответствия между способностями участников и их поведением любой группе неизбежно требуется время. Удовлетворенность качеством ролевого репертуара коллег на первом этапе не отличается от этого же показателя в ролевых командах. Однако беспредметное, и в силу этого весьма опасное, напряжение, видимо, уже формируется в группе, что выражается по сравнению с «ролевыми» командами в сниженных на уровне тенденции показателях интереса и удовлетворенности взаимодействием в целом.

Определение роли в ролевом подходе, наоборот, происходит непосредственно на практике, а самоанализ игроков в соответствии с подходом весьма сжат и конкретен. И если выбранная интеллектуальная роль представляется игроку «наилучшей» или «наиболее свойственной» из всех оставшихся, то командная роль является для него отражением лишь одного из умений среди многообразия рядоположенных компетентностей. Как следствие, конфликтные ситуации в командах, укомплектованных на основе ролевого подхода, возникают реже, иллюзий относительно поведения друг друга также наблюдается меньше, в силу чего и эмпирические показатели согласованности оценок по качеству и времени и степень совпадения ролей, определенных до и во время эксперимента, на уровне тенденции оказываются выше. Но при этом большая гибкость в реализации командной роли тесно связана с ее меньшей - по сравнению с интеллектуальной ролью - яркостью $(\mathrm{p}=0,010)$, а значит, участникам требуются дополнительные усилия, чтобы внести ясность относительно сфер ответственности в команде.

Таким образом, на этапе первого шага применение типологического подхода приводит к тому, что процесс распределения ролей частично заменяется стремлением игроков к самопрезентации, облегчая нахождение ими «благодарных зрителей», но одновременно с этим латентно разобщая команду как группу. Следует, однако, добавить, что на эффективности команд, как показывают дополнительные данные этого же исследования, такие особенности подхода на этапе первого шага еще не сказывается, хотя и создают неблагоприятные предпосылки для последующих этапов. В это же время применение ролевого подхода способствует более затратному и длительному, но и более однозначному процессу формирования системы ролей. Добавим, что процесс этот для «ролевых» команд оказывается умеренно трудоемким, отнимая часть имеющихся у них ресурсов. Полученные данные согласуются с прак- тикой применения «типологических» команд для краткосрочных проектов, а «ролевых» - для решения более длительных задач [8].

На втором этапе, в условиях стабильности, команды, укомплектованные на основе ролевого подхода, продолжают сходным образом разрешать вопросы ролевого распределения, что проявляется в сохранении прежнего уровня согласованности оценок по времени и качеству выполнения ролей, повышении интереса к взаимодействию на уровне тенденции и значимо выраженном повышении общей удовлетворенности взаимодействием ( $\mathrm{p}=$ $0,050)$, удовлетворенности ролевым репертуаром коллег $(\mathrm{p}=0,010)$ и яркости ролевого репертуаpa $(\mathrm{p}=0,050)$. Подобное сочетание характеристик процесса распределения ролей имеет весьма положительные перспективы, в силу того что демонстрирует формирование понимания и принятия членов команды особенностей друг друга. Очевидно, что при использовании ролевого подхода с течением времени участие в командном взаимодействии становится для игроков все более приятным и интересным, как следствие, снижая стресс от процесса совместной деятельности в ходе решения профессиональных задач.

В то же время команды, укомплектованные на основе типологического подхода, на втором этапе сосредотачиваются на вопросах принятия и отторжения как аспекте ролевого распределения. Команды демонстрируют сравнительное снижение общей удовлетворенности совместной деятельностью $(\mathrm{p}=0,010)$ и отсутствие динамики в интересе квзаимодействию при значимом снижении согласованности оценок по времени, затраченному на выполнение роли ( $=0,050)$. Иными словами, восприятие группой каждого индивида становится рассогласованным, и командное взаимодействие, по сути, распадается на ряд диадических. Ситуация усугубляется и отсутствием динамики в оценке яркости ролей коллег, по-прежнему несколько более высокой, нежели в ролевых командах, а значит, в атмосфере разногласий каждый из членов команды продолжает быть уверенным в точности своего восприятия. Заслуживает внимания также и тот факт, что степень соответствия теоретической и эмпирической ролевых структур в «типологических» командах в условиях стабильности не имеет динамики, то есть содержательной перестройки системы ролей по-прежнему еще не происходит.

Таким образом, если в «ролевых» командах при относительно сниженной эффективности процесс позиционирования протекает корректно, то в «типологических» командах он сопряжен с существенными трудностями. 


\section{Горизонты психологии}

Однако применение типологического подхода приводит и к ряду конструктивных изменений в системе ролей. Так, в командах наблюдается значимое повышение удовлетворенности качеством ролевого репертуара коллег $(\mathrm{p}=0,050)$ с сохранением достигнутого уровня согласованности оценок по качеству исполнения роли, а значит, смена этих оценок происходит достаточно синхронно. Таким образом, в «типологических» командах с течением времени постепенно зарождается принятие истинных индивидуальных особенностей коллег, что создает положительную перспективу конструктивного командного взаимодействия. По всей видимости, сложность пути, который приводит участников к осознанию истинных особенностей друг друга, может быть использован как достаточно весомый стимул к полноценному рефлексивному обсуждению личностных особенностей и диспозиций всех членов команды. Учитывая постулируемую ролевым подходом значимость интеллектуальных ролей, закономерно ожидать, что корректность их проявления должна неким образом отслеживаться, чему и могут способствовать результаты деятельности в условиях стабильности.

Третий этап эксперимента представляет собой сочетание условий изменений и фактора времени, являющееся естественным и весьма актуальным в силу того, что деятельность многих команд в определенный период своего развития неизбежно становится ориентирована на разрешение неожиданно возникших кризисных ситуаций. В этих сложных условиях команды, укомплектованные на основе типологического подхода, достигают выраженного прогресса в отношении продуктивного ролевого распределения. Так, согласованность оценок по качеству исполнения роли возрастает значимо ( $\mathrm{p}=0,050)$, по времени - на уровне тенденции, причем в последнем случае результат оказывается максимальным для всех трех условий эксперимента. Также сохраняется преимущество типологического подхода над ролевым по параметру яркости ролевого репертуара коллег ( $\mathrm{p}=0,010)$, фактического уровня гетерогенности $(\mathrm{p}=0,010)$ и на уровне тенденции степени соответствия эмпирической, отраженной в восприятии участников, ролевой структуры и изначально заданной, теоретической.

Иными словами, в условиях изменений реализация типологического подхода становится более предсказуемой. Причиной этого, вероятно, является факт того, что стоящий за интеллектуальной ролью психологический тип, как проявление базовых личностных ориентаций, актуализируется в стрессовых условиях посредством проявления специфи- ческих защитных механизмов [11]. Как следствие, исчезают негативные эффекты самопрезентации, и психологический тип чаще напрямую определяет выбор соответствующей ему интеллектуальной роли. Данный эффект положительно влияет на выравнивании ролевой структуры в соответствии с теоретическими требованиями типологического подхода. Игроки чаще исполняют именно те роли, склонность к которым была определенна до начала эксперимента, и достигают большей ясности относительно ролевого поведения друг друга.

Следует добавить, что дополнительные данные исследования на уровне тенденции демонстрируют снижении эффективности «типологических» команд, однако возможности для раскрытия рефлексивного потенциала группы при этом дополнительно увеличиваются благодаря большей корректности восприятия и реализации ролей игроками, а также возникновения возможности сопоставить отчетливую смену ролевого поведения игроков в зависимости от условий совместной деятельности.

В командах, укомплектованных на основе ролевого подхода, в аналогичных условиях происходят иные изменения. Отношение членов команды к процессам, в ней происходящим, также становится вполне ровным: динамики степени удовлетворенности взаимодействием не наблюдается, более того, на уровне тенденции имеет место повышение удовлетворенности качеством ролевого репертуаpa коллег. Однако внесение изменений в деятельность таких команд приводит к неконтролируемой смене ролей, что разрушает ранее достигнутый баланс и приводит к частичному регрессу ролевого распределении. Согласованность мнений участников относительно ролевого поведения коллег на уровне тенденции понижается, а яркость ролевого репертуара необоснованно повышается $(\mathrm{p}=$ $0,010)$, порождая потенциально деструктивные искажения в восприятии командой поведения каждого ее члена. Степень соответствия эмпирической и теоретической ролевых структур также значимо понижается (p = 0,010) и уступает аналогичному показателю в «типологических» командах: наблюдается большее рассогласование между ожидаемой и реализуемой ролями участников. Как следствие, количество членов команды, выполняющих несвойственные им роли, существенно повышается $(\mathrm{p}=0,010)$.

В итоге, если в условиях изменений типологический подход задает прочную систему интеллектуальных ролей, удерживающую команду как единое целое за счет большей своей статичности, то ролевой подход, наоборот, предоставляет из- 


\section{Психология и психотехника 11(98) • 2016}

лишнюю легкость смены роли, приводящую к рассогласованию системы командных ролей.

\section{Практические возможности и ограничения применения базовых подходов к комплектованию команд}

Вопреки тому что оба подхода в теории предполагают, что создают достаточные условия для успешного ролевого распределения, так как позволяют отобрать в команду только индивидов, по своим качествам потенциально включенных в продуктивное ролевое взаимодействие, на практике команды каждого типа приобретают особую специфику. Ролевой подход обеспечивает большую предсказуемость и планомерность ролевого распределения в стандартных рабочих условиях. Реализация типологического подхода представляется более сложной за счет неизбежности возникновения временных затрат при перестройке системы ролей от псевдоролевых, основанных на отдель- ных несбалансированных навыках, на истинные интеллектуальные. Однако сопутствующим эффектом достижения ролевого баланса в этом случае становится принятие индивидами истинных особенностей ролевого поведения друг друга, что, в свою очередь, является основой для будущей более полной рефлексии командного потенциала.

Учитывая, что применение того или иного подхода к комплектованию команды, как правило, определяется личными профессиональными предпочтениями ее руководителя, проведенное исследование позволяет составить достаточно полную картину об основных внутренних процессах, протекающих в команде, в зависимости от применения каждого из подходов. Детальный анализ данных особенностей процесса распределения ролей создает дополнительные возможности для выявления первоисточников таких проблем, как колебания эффективности и внутригрупповые конфликты, что, безусловно, должно облегчить процесс создания и управления командой.

\section{Список литературы:}

1. Адизес И. К. Идеальный руководитель: Почему им нельзя стать и что из этого следует. М.: Альпина Паблишер, 2014. - 262 c.

2. Андреева Г. М., Богомолова Н. Н., Петровская Л. А. Зарубежная социальная психология XX столетия: Теоретические подходы: Учеб. пособие для вузов. - М.: Аспект Пресс, 2001. - 288 с.

3. Белбин Р. М. Типы ролей в командах менеджеров. М.: Нірро, 2003. - 240 с.

4. Бриггс-Майерс И., Майерс П. МВТІ: определение типов. М.: Бизнес Психологи, 2010. - 256 с.

5. Геллерт М., Новак К. Все о командообразовании: руководство для тренеров. М.: Вершина, 2006. - 352 с.

6. Гоффман Э. Представление себя другим в повседневной жизни. М.: Канон-Пресс, 2000. - 304 с.

7. Жуков Ю. М., Журавлев А. В., Павлова Е. Н. Технологии командообразования. М.: Аспект пресс, 2008. - 320 с.

8. Кейрси Д. Пожалуйста, пойми меня - II. М.: Черная Белка, 2011. - 320 c.

9. Льюис Дж. Управление командой. Спб.: Питер, 2004. - 160 с.

10. Маргерисон Ч. «Колесо» командного управления: Путь к успеху через систему управления командой. Днепропетровск: Баланс Бизнес Букс, 2004. - 208 с.

11. Роббинс Х., Финли М. Почему не работают команды? Что идет не так, и как это исправить. М.: Добрая книга, 2005. $304 \mathrm{c.}$

12. Родионова Д. Е. Исследование особенностей защитно-коупинговых стратегий в связи с типологическими характеристиками личности // Психологическая наука и образование. - 2007. - № 5. - С. 259-266.

13. Юнг К. Г. Психологические типы. - СПб.: Азбука, 2001. - 736 с.

14. Ярошевский М. Г., Юревич А. В., Аллахвердян А. Г. Программно-ролевой подход и современная наука // Вопросы психологии. - 2002. - №6. С. 3-18.

15. Benne K. D., Sheats P. Functional Roles of Group Members // Group Facilitation: A research \& Application Journal. - 2007. N 8. - P. $30-35$.

16. Joshi A., Roh H. The role of context in work team diversity research: A meta-analytic review // Academy of Management Journal. - 2009. - V. 52. - P. 599-627.

17. Katzenbach J. R., Smith D. K. The Discipline of Teams. NY: John Wiley \& Sons, 2001. - 257 p.

18. Stempfle J., Huebner O., Badke-Schaub P. A functional theory of task role distribution in work groups // Group Processes and Intergroup Relations. - 2001. - V. 4 (2). - P. 138-159.

\section{References (transliterated):}

1. Adizes I. K. Ideal'nyi rukovoditel': Pochemu im nel'zya stat' i chto iz etogo sleduet. M.: Al'pina Pablisher, 2014. - 262 s.

2. Andreeva G. M., Bogomolova N. N., Petrovskaya L. A. Zarubezhnaya sotsial'naya psikhologiya KhKh stoletiya: Teoreticheskie podkhody: Ucheb. posobie dlya vuzov. - M.: Aspekt Press, 2001. - $288 \mathrm{~s}$.

3. Belbin R. M. Tipy rolei v komandakh menedzherov. M.: Hippo, 2003. - $240 \mathrm{~s}$.

4. Briggs-Maiers I., Maiers P. MBTI: opredelenie tipov. M.: Biznes Psikhologi, 2010. - 256 s.

5. Gellert M., Novak K. Vse o komandoobrazovanii: rukovodstvo dlya trenerov. M.: Vershina, 2006. $-352 \mathrm{~s}$. 
6. Goffman E. Predstavlenie sebya drugim v povsednevnoi zhizni. M.: Kanon-Press, 2000. - 304 s.

7. Zhukov Yu. M., Zhuravlev A. V., Pavlova E. N. Tekhnologii komandoobrazovaniya. M.: Aspekt press, 2008. - 320 s.

8. Keirsi D. Pozhaluista, poimi menya - II. M.: Chernaya Belka, 2011. - $320 \mathrm{~s}$.

9. L'yuis Dzh. Upravlenie komandoi. Spb.: Piter, 2004. - 160 s.

10. Margerison Ch. «Koleso» komandnogo upravleniya: Put' k uspekhu cherez sistemu upravleniya komandoi. Dnepropetrovsk: Balans Biznes Buks, 2004. - 208 s.

11. Robbins Kh., Finli M. Pochemu ne rabotayut komandy? Chto idet ne tak, i kak eto ispravit'. M.: Dobraya kniga, 2005. - 304 s.

12. Rodionova D. E. Issledovanie osobennostei zashchitno-koupingovykh strategii v svyazi s tipologicheskimi kharakteristikami lichnosti // Psikhologicheskaya nauka i obrazovanie. - 2007. - № 5. - S. 259-266.

13. Yung K. G. Psikhologicheskie tipy. - SPb.: Azbuka, 2001. - 736 s.

14. Yaroshevskii M. G., Yurevich A. V., Allakhverdyan A. G. Programmno-rolevoi podkhod i sovremennaya nauka // Voprosy psikhologii. - 2002. - №6. S. 3-18.

15. Benne K. D., Sheats P. Functional Roles of Group Members // Group Facilitation: A research \& Application Journal. - 2007. N 8. - P. 30 -35.

16. Joshi A., Roh H. The role of context in work team diversity research: A meta-analytic review // Academy of Management Journal. - 2009. - V. 52. - P. 599-627.

17. Katzenbach J. R., Smith D. K. The Discipline of Teams. NY: John Wiley \& Sons, 2001. - 257 p.

18. Stempfle J., Huebner O., Badke-Schaub P. A functional theory of task role distribution in work groups // Group Processes and Intergroup Relations. - 2001. - V. 4 (2). - P. 138-159.11. 